\title{
Nghiên cứu đánh giá khả năng kháng nấm mốc cho vật liệu xây dựng
}

\author{
Trần Ngọc Trang ${ }^{1 *}$, Lê Thị Song ${ }^{1}$, Lê Cao Chiến ${ }^{1}$ \\ ${ }^{1}$ Trung tâm Thiết bị, Môi trường \& An toàn lao động - Viện Vật liệu xây dựng
}

\section{TỪ KHÓA}

\section{Kháng nấm mốc}

Vật liệu xây dựng

Thử nghiệm kháng nấm mốc

Vật liệu chống ẩm

Vật liệu kháng nấm mốc

Môi trường khí hậu trong nhà

\begin{abstract}
TÓM TẮT
Việt Nam là một quốc gia có khí hậu nhiệt đới gió mùa, nóng ẩm, có đường bờ biển trải dài từ Bắc vào Nam. Do vậy môi trường không khí trong nhà thường dễ bị ẩm ướt. Đây là điều kiện lý tưởng để nấm mốc có thể phát triển gây ảnh hưởng xấu đến sức khỏe con người và làm biến đổi thành phần, tính chất vật liệu tạo ra những mối nguy hại đến công trình xây dựng. Nghiên cứu thử nghiệm khả năng kháng nấm mốc của Vật liệu xây dựng đang được thực hiện tại Trung tâm Thiết bị, Môi trường và An toàn Lao động - Viện Vật liệu xây dựng theo tiêu chuẩn ASTM D3273 - 16. Phương pháp thử nghiệm sử dụng ba chủng nấm mốc: Aureobasidium pullulans ATCC 9348, Aspergillus niger ATCC 6275 và Penicillium Sp ATCC 9849 được phân lập trong 10 đến 14 ngày. Khi các chủng nấm đạt đến độ phát triển tối ưu, tiến hành cấy các bào tử nấm này sang môi trường đất chứa $25 \%$ rêu bùn, độ pH 5,5 đến 7,0. Nghiên cứu tiến hành so sánh và đánh giá khả năng kháng nấm mốc của các loại mẫu thử: Tấm trần thạch cao kháng khuẩn; tấm sợi khoáng tiêu âm; tấm thạch cao thông thường và tấm gỗ ép $\mathrm{MDF}$, sau khi phơi nhiễm trong môi trường chứa các bào tử nấm này ở điều kiện nhiệt độ $32,5 \pm 1{ }^{\circ} \mathrm{C}$ và độ ẩm $95 \pm 3 \%$ trong thời gian 04 tuần. Bài viết này đề cập đến nội dung của phương pháp đánh giá, kết quả đánh giá và so sánh khả năng kháng nấm mốc của một số vật liệu xây dựng kháng nấm mốc và thông thường trên thị trường Việt Nam.
\end{abstract}

\begin{abstract}
Vietnam has a tropical monsoon climate, is hot and humid, and has a coastline extending from north to south. The indoor environment of buildings is typically prone to be moist. This is an ideal condition for mold to grow, which negative effects on human health, change the composition and properties of materials that cause hazards for buildings,.... Research on mold resistance testing of building materials is being made at Center for Equipment, Environment and Labour Safety - Vietnam Institute for Building Materials in accordance with ASTM D3273-16. Test methods used three mold strains: Aureobasidium pullulans ATCC 9348, Aspergillus niger ATCC 6275 and Penicillium Sp ATCC 9849 were isolated for 10 to 14 days. Once the strain has reached optimal growth, inoculate these spores into soil medium containing $25 \%$ peat moss ( $\mathrm{pH} 5.5$ - 7.0). A study to compare and evaluate the mold resistance of test samples: antibacterial gypsum ceiling panels, sound absorption mineral fiber Panels; normal gypsum board and MDF board are exposed to an environment containing these fungal spores at a temperature of $32.5 \pm 1{ }^{\circ} \mathrm{C}$ and a humidity of $95 \pm 3 \%$ for 04 weeks. This paper describes the content method, evaluation results, and comparison of mold resistance of some common mold resistant building materials in the Vietnamese market.
\end{abstract}

\section{Giới thiệu}

Nấm mốc có thể tìm thấy ở mọi nơi chúng ta làm việc, sinh sống và vui chơi. Cho dù bên trong hay bên ngoài, trôi nổi trong không khí hay mắc kẹt trên các bề mặt với mọi kích thước và hình dạng, nấm mốc luôn hiện hữu trong môi trường xung quanh con người. Sự phát triển của nấm mốc trên các vật liệu xây dựng thường liên quan đến sự ẩm ướt do ba nguồn chính bao gồm sự thấm nước mưa, nước ngầm hoặc sự ngưng tụ hơi nước trên bề mặt vật liệu. Một số nghiên cứu đã đánh giá tác động của độ ẩm đến tính nhạy cảm của vật liệu xây dựng với sự phát triển của nấm đã cho thấy. Khi độ ẩm thấp, nấm mốc thường không phát triển được trên bề mặt vật liệu cũng như cấu trúc xây dựng. Giá trị độ ẩm tương đối dao động từ $70 \%$ đến $90 \%$ là điều kiện cần thiết cho sự phát triển của nấm mốc trên vật liệu xây dựng, bên cạnh đó nhiều yếu tố khác như hàm lượng chất dinh dưỡng sẵn có, mức độ bào tử nấm, chủng loại nấm mốc cũng ảnh hưởng đến sự phát triển của nấm mốc trong nhà. Các nghiên cứu trước đây cho thấy sự phát triển của nấm mốc phụ thuộc vào thành phần của vật liệu xây dựng. Đặc biệt các vật liệu xây dựng như tấm trần, ván sàn, giấy dán tường và đồ nội thất bằng gỗ, hoặc có nguồn gốc hữu cơ hay sản xuất từ các sản phẩm hữu cơ. Những loại vật liệu này có thể cung cấp nhiều chất dinh dưỡng cho sự phát triển của nấm mốc. Trong tự nhiên, nấm thường thu nhận các 
chất dinh dưỡng bằng cách phá vỡ các polymer phức tạp như tinh bột, xenlulozo và lignin với sự hỗ trợ của các enzym ngoại bào thành dạng dinh dưỡng đơn giản và dễ hấp thụ hơn như đường và axit amin. Một số phụ gia kháng nấm chẳng hạn như natri polyborat, iodopropinyl butylcarbamate (IPBC), và dichlo fluanid, thường được sử dụng để ngăn chặn sự phát triển của nấm mốc trong các loại vật liệu xây dựng dễ bị nhiễm nấm mốc. Tuy nhiên do hiệu quả ngắn hạn của các loại phụ gia này cùng với các mối quan tâm về nguy cơ tiềm ẩn gây ảnh hưởng đến sức khỏe con người nên các loại phụ gia này cũng bị hạn chế sử dụng cho các sản phẩm sử dụng trong nhà. Chiến lược ưu tiên là lựa chọn vật liệu có khả năng kháng nấm mốc một cách tự nhiên và loại bỏ các điều kiện ban đầu để có thể dẫn đến sự phát triển của nấm mốc [1].

Có nhiều loài nấm khác nhau, đa phần các loại nấm mốc đều gây hại. Thuật ngữ "mốc đen” thường sử dụng để chỉ loại nấm mốc có tên khoa học là Stachybotrys chartarum còn gọi là black mold hay toxic black mold. Nấm mốc đen tiết ra mycotoxin là một loại độc tố gây nguy hại cho sức khỏe của con người. Trẻ em, người già và một số đối tượng nhạy cảm với bào tử nấm có thể xuất hiện các triệu chứng như mắt hoặc da mẩn đỏ, ngứa, nghẹt mũi, thở khò khè,... ngay sau khi tiếp xúc với một lượng nhỏ bào tử. Bên cạnh đó, những người khỏe mạnh cũng có thể xảy ra ngộ độc nấm nếu tiếp xúc với mycotoxin nồng độ cao hay tiếp xúc thời gian dài. Các phản ứng nặng có thể bao gồm sốt và thở dốc. Năm 2004, Viện Y học - Hoa kỳ đã tìm thấy bằng chứng liên quan giữa việc tiếp xúc với nấm mốc trong nhà với các triệu chứng đường hô hấp bao gồm ho và thở khò khè ở những người khỏe mạnh bình thường; với các triệu chứng hen suyễn ở những người có bệnh hen suyễn; và với bệnh viêm phổi quá mẫn ở những người dễ bị tình trạng bệnh lý qua trung gian miễn dịch đó. Năm 2009, Tổ chức Y tế Thế giới đã ban hành hướng dẫn bổ sung, WHO Guidelines for Indoor Air Quality: Dampness and Mould (Hướng dẫn của WHO về chất lượng không khí trong nhà: Độ ẩm và nấm mốc). Các nghiên cứu đã chỉ ra đủ bằng chứng dịch tễ học được thực hiện ở các quốc gia khác nhau và trong các điều kiện khí hậu khác nhau để cho thấy rằng con người sống trong các tòa nhà ẩm mốc thì nguy cơ mắc các triệu chứng hô hấp, nhiễm trùng đường hô hấp và bệnh hen suyễn cấp tính đang gia tăng. Có bằng chứng lâm sàng cho thấy việc tiếp xúc với nấm mốc và ẩm ướt liên quan đến các tác nhân vi sinh vật làm tăng nguy cơ mắc các tình trạng hiếm gặp, chẳng hạn như viêm phổi, viêm phế nang dị ứng, viêm mũi họng mãn tính và viêm xoang do nấm dị ứng. Bằng chứng độc học thu được trong các nghiên cứu cho thấy sự xuất hiện của các phản ứng viêm và ngộ độc đa dạng sau khi tiếp xúc với vi sinh vật - bao gồm các bào tử, chất chuyển hóa và các thành phần của chúng $[2,3]$.

Tại Việt Nam kết quả nghiên cứu chất lượng không khí trong nhà được tiến hành tại 3 thành phố lớn là Hà Nội, Đà Nẵng, TP.Hồ Chí Minh về tổng lượng vi khuẩn-vi sinh vật và tổng lượng nấm mốc ở trong nhà đối với 17 phòng điều hòa không khí cho thấy (theo tiêu chuẩn của Singapore - SS 554:2009 - Quy định tổng lượng vi khuẩn, vi sinh vật và tổng lượng nấm mốc có trong không khí trong nhà không được vượt quá trị số $\left.500 \mathrm{cfu} / \mathrm{m}^{3}\right)$, thì có tới 12/17 phòng $(70,6$ \%) lượng vi khuẩn, vi sinh vật vượt giới hạn cho phép; chỉ có 5 phòng $(29,4$ \%) bé hơn giới hạn cho phép. Ở Đà Nẵng không có phòng nào đáp ứng tiêu chuẩn của Singapore về tổng vi sinh vật. Về nấm mốc có tới 16/17 phòng (94\%) có tổng lượng nấm mốc bé hơn trị số TCCP (500 cfu/m $\mathrm{m}^{3}$ ), chỉ có 1 phòng (6 \%) có tổng lượng nấm mốc lớn hơn trị số $500 \mathrm{cfu} / \mathrm{m}^{3}$ [4].

Việc ngăn ngừa sự phát triển của nấm mốc trong những ngôi nhà ở mới xây dựng hoặc nhà hiện hữu không chỉ là vấn đề về thẩm mỹ mà còn đảm bảo sức khỏe và y tế cộng đồng. Do vậy cần thiết phải phân loại khả năng kháng nấm mốc và vi sinh vật tùy thuộc vào khả năng chống lại sự phát triển của vi sinh vật để sử dụng vật liệu một cách hợp lý. Để xác định độ bền của vật liệu và đánh giá khả năng kháng vi sinh vật nói chung và kháng nấm mốc nói riêng thì có nhiều phương pháp tiêu chuẩn khác nhau như: TCVN 9064:2012; TCVN 8555:2010; TCVN 11108:2015; ISO 22196:2011; ISO 27447:2009; ISO 17094:2014; ISO 16869:2008; ASTM E 1054-02; ASTM G22-76; ASTM E3152-18; ASTM D3273-16; ASTM G21-15; JIS Z 2801:2000; JIS Z 2911-2000,... [5]. Các tiêu chuẩn này nhằm đánh giá khả năng chống lại sự phát triển của nấm mốc và vi sinh vật trên bề mặt mẫu thử. Dựa vào các vật liệu khác nhau mà mẫu thử được tiếp xúc với một hoặc vài chủng nấm khác nhau có liên quan và sau đó theo dõi sự phát triển của nấm. Nghiên cứu này nhằm giới thiệu phương pháp đánh giá khả năng kháng nấm mốc của vật liệu xây dựng theo tiêu chuẩn. Phương pháp tiêu chuẩn được sử dụng là ASTM D3273 dùng để đánh giá sự biến dạng do nấm mốc trên bề mặt vật liệu được bảo vệ một cách nhanh chóng. Ngoài ra, thử nghiệm ASTM D3273 cũng nhằm mục đích thiết lập khả năng kháng cự tương đối của vật liệu đối với sự lây lan của nấm mốc trong điều kiện nấm phát triển tối ưu. Quá trình ủ được diễn ra trong một môi trường được kiểm soát chặt chẽ với các kích thước được tiêu chuẩn hóa trong khoảng thời gian 4 tuần [5].

\section{Tổng quan nghiên cứu về kháng nấm mốc trên vật liệu xây dựng}

Sự phân hủy sinh học là do sự có mặt của vi sinh vật như vi khuẩn và nấm làm biến đổi bề mặt hoặc vật liệu một cách nghiêm trọng. Sự phân hủy sinh học bởi vi sinh vật có thể được chia thành bốn loại sau:

i) Phân hủy sinh học tác động vật lý hoặc cơ học: vi sinh vật không ăn vật liệu, tuy nhiên dưới áp lực do sự chuyển động hoặc tăng trưởng của vi sinh vật làm cho vật liệu bị phá vỡ;

ii) Phân hủy sinh học ảnh hưởng tới tính thẩm mỹ của vật liệu: Sự có mặt của vi sinh vật hoặc sản phẩm của nó, không làm hỏng vật liệu những làm ảnh hưởng đến khả năng chấp nhận của vật liệu.

iii) Phân hủy sinh học bởi đồng hóa hóa học: Vi sinh vật sử dụng vật liệu làm nguồn cung cấp năng lượng hoặc thức ăn.

iv) Phân hủy sinh học bởi cơ chế hòa tan:Vi sinh vật có thể bài tiết ra các chất làm biến dạng hoặc hỏng vật liệu dẫn tới làm hư hỏng vật liệu.

Sự tương tác giữa nấm mốc trong không khí và cơ thể con 
người đã bị bỏ qua trong một thời gian dài. Nhưng, những hội chứng bệnh nhà kín hay hội chứng nhà cao tầng (Sick Building Syndrome SBS) trong những năm 1970 và mối tương quan của nó với nồng độ cao của các chủng nấm mốc trong nhà đã thu hút các hướng nghiên cứu về tác động của nấm mốc trong nhà. Theo Al-Hunaiti và cộng sự [6] bụi trong nhà chứa nhiều loại sinh vật, chất ô nhiễm gây độc hại cho con người. Sự tương tác giữa các yếu tố môi trường, đặc tính vật liệu và đặc điểm của nấm mốc là những yếu tố quyết định đến sự phát triển của chúng trong nhà. Sự phát triển của nấm mốc có thể xảy ra trực tiếp trên bê tông, trên bề mặt sơn và một số vật liệu xây dựng thậm chí có thể bị nhiễm nấm trước. Độ ẩm, điều kiện thông gió và nhiệt độ là một trong những yếu tố chính liên quan đến ô nhiễm không khí trong nhà và sự phát triển của nấm mốc. Cường độ tác động của hệ vi sinh vật phụ thuộc vào mật độ dân cư, lưu thông không khí và đặc điểm dân cư. Các nguồn gây ô nhiễm sinh học chủ yếu đến từ không khí bên ngoài, do con người gây ra và từ vật liệu xây dựng.

Nguồn gốc những thiệt hại của vi sinh vật tác động tới các tòa nhà là những thay đổi về điều kiện khí hậu xảy ra trong việc sử dụng vật liệu xây dựng, cùng với ô nhiễm đô thị, chất lượng vật liệu xây dựng thấp và các vấn đề về thiết kế và thi công. Những thiệt hại trong hầu hết các tòa nhà có mức độ suy thoái cao và lão hóa sớm, có thể ảnh hưởng tiêu cực đến tính chất của tòa nhà, chẳng hạn như tính an toàn, thẩm mỹ và độ bền. Adams và cộng sự [7] thực hiện đánh giá độ phơi nhiễm của các tòa nhà, cường độ dòng khí ngoài trời bên trong các tòa nhà thông gió khác nhau. Tỷ lệ thông gió ảnh hưởng đến sự đóng góp tương đối của không khí ngoài trời theo cách thông gió tự nhiên hoặc cửa sổ mở đến hệ vi sinh vật tương tự như không khí ngoài trời và ít ảnh hưởng bởi các nguồn khác. Những yếu tố này cộng với thiết kế kiến trúc và có thể giảm bớt liên quan đến việc kiểm soát độ ẩm, thông gió tòa nhà, hô hấp không khí và kỹ thuật xử lý nhiệt.

Nghiên cứu của Johansson và cộng sự đã khẳng định rằng nấm mốc có thể tồn tại trong thời gian và điều kiện không thuận lợi đối với sự phát triển của chúng. Tuy nhiên, các điều kiện hầu như không thay đổi theo thời gian trong một tòa nhà, vì nhiệt độ và độ ẩm khác nhau có thể thuận lợi cho sự phát triển của nấm mốc [8]. Các bức tường trong nhà đóng vai trò là kết cấu ngăn chia có liên quan đến đặc tính an toàn và hiệu suất tòa nhà. Các lớp sơn tường được áp dụng trên tường trong và ngoài khi hoàn thiện bề mặt do chúng ảnh hưởng đáng kể đến độ bền, đặc tính bảo vệ về mặt thẩm mỹ và định giá các ngôi nhà. Bashir và Hafeez kết luận rằng nấm phát triển trên bề mặt sơn tường là dấu hiệu cảnh báo có đầy đủ nguồn thức ăn hữu cơ cho vi sinh vật ở trên tường, có thể gây hại cho sức khỏe con người. Trong thành phần của sơn có chứa một số chất dinh dưỡng cho vi sinh vật phát triển nên sơn dễ bị phân hủy sinh học từ sự phát triển của các vi sinh vật ở cả trạng thái khô và ướt làm thay đổi chức năng của màng sơn. Ngoài ra, các tác giả chỉ ra rằng chất lượng sơn cần phải đảm bảo và có khả chống ẩm sẽ làm giảm nguy cơ phát triển nấm mốc trên tường [9].

Nghiên cứu của Guerra cho thấy các tấm cứng, tấm thạch cao và tấm bìa các tông có xu hướng dễ bị nhiễm và là môi trường sinh sôi của vi sinh vật. Theo Parjo và cộng sự thì các chủng nấm Aspergillus niger, Stachybotrys, Cladosporium thường được tìm thây trên các tấm ván phủ, bên cạnh đó các chủng nấm Aureobasidium, Alternaria và Penicllium, có thể tìm thấy trên màng sơn khô. Hirakawa và cộng sự nhận thấy sự phát triển của nấm mốc trên bề mặt phân cách giữa các lớp sơn và trên mặt phân cách giữa lớp sơn và chất nền [10].

Mensah-Attipoe và cộng sự nhấn mạnh rằng nấm phát triển có thể thấy trên vật liệu xây dựng là do độ ẩm kéo dài trên bề mặt của chúng và sự gia tăng của sinh khối nấm mang lại sự khác biệt của đặc tính kháng nấm mốc. Nhiều nghiên cứu khác cũng đã chỉ ra rằng sự phát triển của nấm mốc được tạo ra khi sự kết hợp của nhiệt độ và độ ẩm vượt quá giới hạn đường cong tăng trưởng tính toán [11].

Theo Andersen và cộng sự thì yếu tố quan trọng cũng cần phải xem xét đến việc xác định các chủng nấm có trong một tòa nhà. Việc xác định các chủng nấm thường bằng cách quan sát hình thái của chúng từ khi bắt giữ bào tử nấm hoặc sau khi nuôi cấy. Những phương pháp này ước tính có khoảng 90 chủng nấm mốc được coi là phổ biến và quan trọng trong nhà [12]. Các chủng nấm mốc có thể phân hủy hầu hết tất cả các loại vật liệu tự nhiên và nhân tạo, đặc biệt nếu vật liệu bị hút ẩm. Ngay cả những vật liệu hoàn toàn vô cơ vẫn sẽ bị nấm mốc nếu chúng hấp thụ bụi, là môi trường lý tưởng cho các chủng nấm fumigatus và versicolor. Vật liệu gỗ vẫn là một trong những vật liệu được sử dụng phổ biến và rất dễ bị ẩm mốc phát triển. Nó có thể bị nhiễm các chủng nấm Cladosporium, $\mathrm{P}$. brevicompactum và P.expansum là những chủng nấm tại các xưởng cưa. Việc sấy khô bằng lò làm cho bề mặt của gỗ dễ bị nấm mốc phát triển hơn, vì bề mặt khi đó sẽ có hàm lượng nitơ cao hơn và phân tử cacbonhydrat thấp. Một số vật liệu gỗ biến tính thường được sử dụng như ván gỗ dăm OSB, ván gỗ ép và ván gỗ MDF dễ bị các chủng nấm Aspergillus, Trichoderma và Penicillium phát triển nhanh hơn gỗ đặc, gỗ acyl hóa và vật liệu nhựa gỗ tổng hợp gốc polyetylen [13].

Tấm thạch cao đúc sẵn là vật liệu tường trong được sử dụng phổ biến gần đây tại Việt Nam. Tuy nhiên do làm bằng giấy, được sử dụng để gia cố vật liệu nên các tấm có độ bền cao dễ bị nấm mốc phát triển, đặc biệt là chủng nấm cellulytic $S$. chartarum. Bản thân thạch cao (được sử dụng để trát tường) cũng có thể hỗ trợ sự phát triển của nấm do hàm lượng dinh dưỡng tương đối của thạch cao và các chất phụ gia làm cho sản phẩm dễ hút ẩm ở độ ẩm thấp hơn. Nhiều bề mặt trong nhà hiện nay được dán tường và điều này làm tăng tính nhạy cảm của tường với nấm mốc, vì giấy và keo là môi trường rất tốt cho hầu hết các chủng nấm mốc trong nhà [14].

Vật liệu nhựa ngày càng được sử dụng rộng rãi, nhựa polyetylen và $\mathrm{PVC}$ dễ bị ảnh hưởng bởi nấm mốc phát triển, vì nấm mốc sử dụng hầu hết các chất hóa dẻo. Từ năm 1957, Berk và cộng sự cho thấy 90 trong số 127 chất hóa dẻo khác nhau có thể bị phân hủy bởi các loại nấm mốc thường thấy trên các bề mặt trong nhà. Ngay cả bông thủy tinh cách nhiệt và tầm trần bằng sợi thủy tinh (chứa $10 \%$ nhựa urê phenol-fomandehit) cũng là môi trường hỗ trợ sự phát triển 
của nấm mốc, đặc biệt là chủng nấm A.versicolor và Penicillium sp. Nhựa polyurethanes được sử dụng trong nhiều vật liệu tổng hợp như xốp cách nhiệt rất dễ bị nấm mốc tấn công và chúng phải được kiểm tra định kỳ về sự phân huỷ sinh học bởi vi sinh vật. Đặc biệt là các chủng nấm mốc Paecilomyces variotii, T. harzianum, và Penicillium sp. thường xuyên phát triển trên vật liệu xốp cách nhiệt trên cơ sở urê-formaldehyde [15].

Đối với các loại sản phẩm sơn có thể làm tăng và giảm độ nhạy cảm của một số loại vật liệu cơ bản nhất định. Sơn nước, được sử dụng phổ biến nhất ở Việt Nam là loại sơn rất dễ bị nấm mốc phát triển và phải được kiểm tra thường xuyên. Tuy nhiên, vật liệu nền cho sơn cũng rất quan trọng đối với sự phát triển của nấm mốc. Chủng nấm mốc Aureobasidium pullulans là chủng phổ biến nhất trên các loại sơn và các chủng Aspergillus, Alternaria và Cladosporium phát triển mạnh trên sơn acrylic [16].

Sự phát triển của nấm mốc trong các lõi lọc không khí và trong các ống thông gió là điều cần đặc biệt quan tâm, vì hệ thống thông gió sẽ hoạt động như môi trường mang bào tử nấm hiệu quả. Trong ống thông gió nấm mốc thường tăng trưởng trên các bề mặt sơn và đặc biệt là trong bụi, mặc dù một số vật liệu cách nhiệt bằng sợi thủy tinh có thể hỗ trợ tăng trưởng [17].

\section{Phương pháp nghiên cứu}

\subsection{Phương pháp nghiên cứu}

Nghiên cứu đánh giá khả năng kháng nám mốc của vật liệu xây dựng dựa trên ASTM D 3273-16: Standard Test Method for Resistance to Growth of Mold on the Surface of Interior Coatings in an Environmental Chamber (Phương pháp thử tiêu chuẩn về khả năng chống lại sự phát triển của nấm mốc trên bề mặt lớp phủ nội thất trong phòng môi trường). Vật liệu nghiên cứu là: gỗ, tấm thạch cao, tấm cách nhiệt, tấm sợi khoáng tiêu âm Celotexdo,..... và các vật liệu dễ nhiễm nấm mốc khác. Thử nghiệm sử dụng 03 chủng nấm mốc Aureobasidium pullulans ATCC\# 9348, Aspergillus niger ATCC\# 6275 và Penicillium Sp. ATCC\# 9849 và ủ 03 chủng nấm này phát triển trong vòng từ 10 đến 14 ngày. Sau đó nhỏ dung dịch huyền phù chứa 03 loại nấm này vào khay đất chứa $25 \%$ rêu bùn, độ pH 5,5 đến 7,0 đã ổn định $24 \mathrm{~h}$ trong tủ nhiệt ẩm. Đặt các đĩa thạch tại các vị trí dự định treo mẫu khác nhau trong tủ có chứa đất đã chuẩn bị để kiểm tra sự phát triển của nấm mốc, sau 5 đến 7 ngày ủ thạch nấm sẽ phát triển gần hết hoặc hết đĩa thạch. Nhiệt độ và độ ẩm thích hợp là: 32,5 $\pm 1{ }^{\circ} \mathrm{C}$ và độ ẩm $95 \%$. Khi môi trường thử nghiệm đã đạt yêu cầu, tiến hành treo mẫu thử cách nhau, không chạm vào nhau thẳng đứng cách bề mặt đất $75 \mathrm{~mm}$. Các tấm mẫu đối chứng (mẫu không xử lý kháng nấm mốc) cũng được treo thẳng đứng xen kẽ trong môi trường thử nghiệm.

\subsection{Phương pháp đánh giá}

Sau khi kết thúc thời gian thử nghiệm, các mẫu thử sẽ được đánh giá cấp độ phát triển nấm mốc. Cấp độ phát triển nấm mốc được đánh giá theo 10 cấp phân loại theo tỷ lệ phần trăm diện tích mẫu bị tác động, trong đó cấp 10 là bề mặt không bị tác động còn cấp 0 là bề mặt mẫu bị tác động hoàn toàn. Quy trình đo diện tích nhiễm nấm được xử lý bằng chương trình phần mềm Jimage.

Bảng 1. Đánh giá cấp độ kháng nấm mốc theo ASTM D 3273 - 16.

\begin{tabular}{|c|c|}
\hline Diện tích nhiễm nấm $\boldsymbol{X}, \boldsymbol{\%}$ & Cấp kháng nấm \\
\hline 0 & 10 \\
\hline $1-10$ & 9 \\
\hline $11-20$ & 8 \\
\hline $21-30$ & 7 \\
\hline $31-40$ & 6 \\
\hline $41-50$ & 5 \\
\hline $51-60$ & 4 \\
\hline $61-70$ & 3 \\
\hline $71-80$ & 2 \\
\hline $81-90$ & 1 \\
\hline $91-100$ & 0 \\
\hline
\end{tabular}

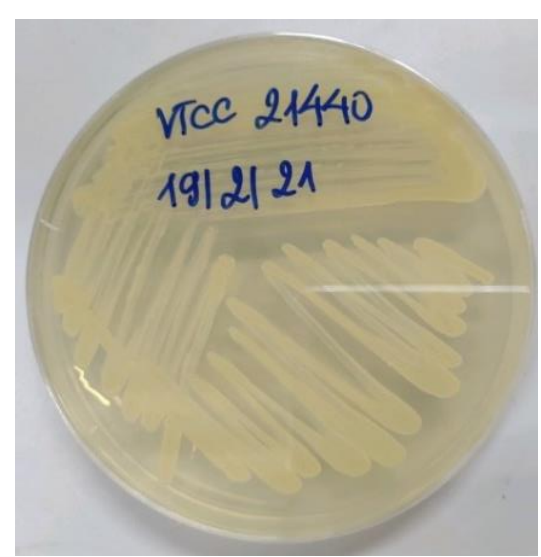

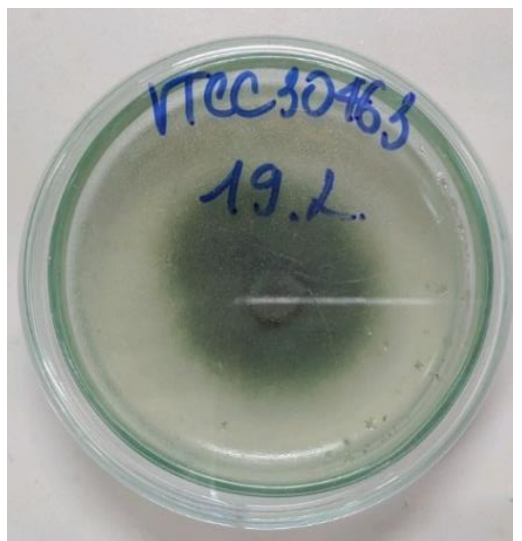

(a) Ba chủng nấm được sử dụng trong nghiên cứu

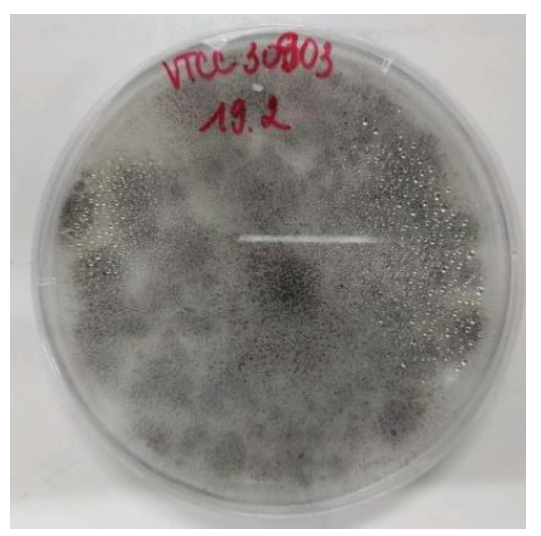



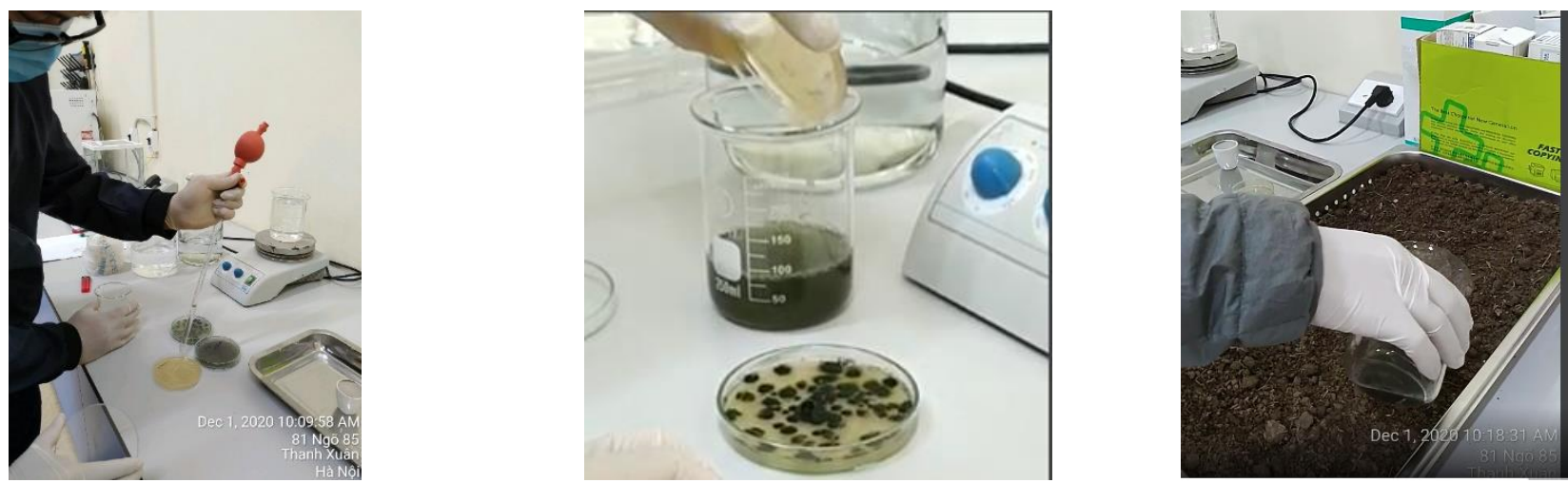

(b) Chuẩn bị dung dịch huyền phù nấm và đất thử nghiệm
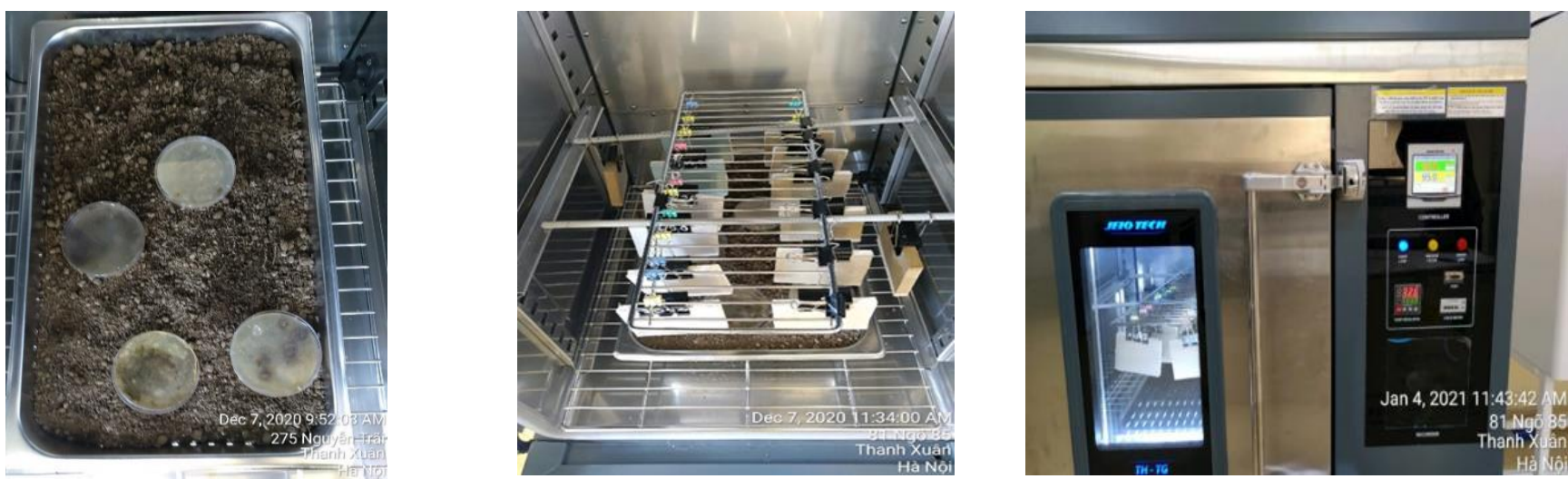

(c) Kiểm tra môi trường thử nghiệm

Hình 1. Qui trình thử nghiệm khả năng kháng nấm mốc của vật liệu xây dựng.
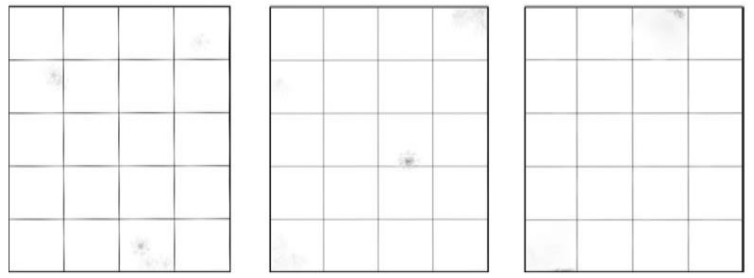

Cấp độ 9 (1-10\% diện tích nhiễm nấm)
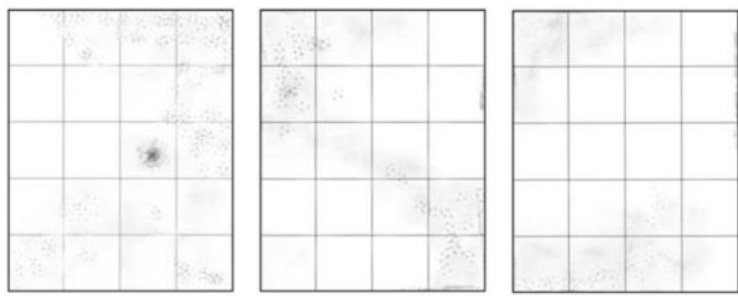

Cấp độ 7 (21-30 \% diện tích nhiễm nấm)
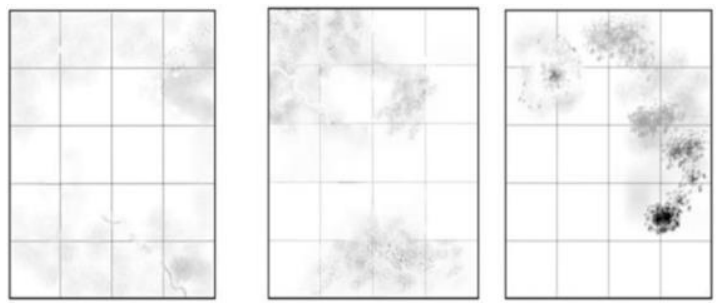

Cấp độ 5 (41-50\% diện tích nhiễm nấm)
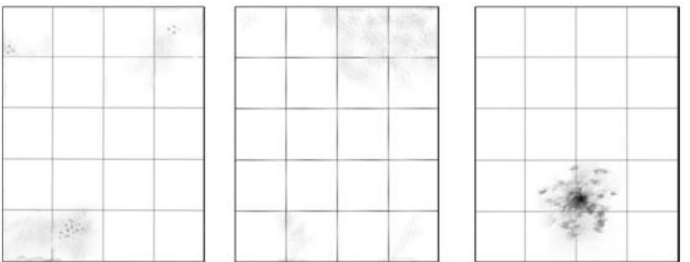

Cấp độ 8 (11-20\% diện tích nhiễm nấm)
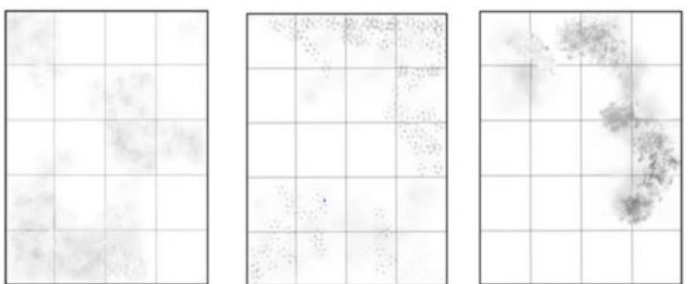

Cấp độ 6 (31-40\% diện tích nhiễm nấm)
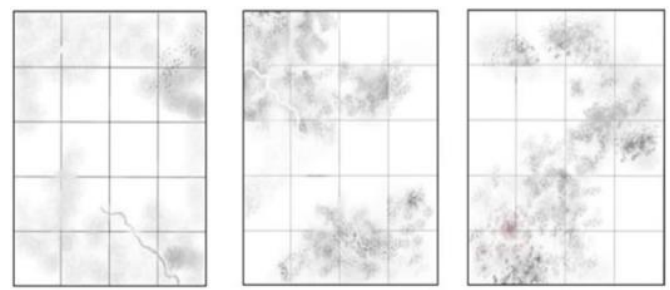

Cấp độ 4 (51-60\% diện tích nhiễm nấm) 

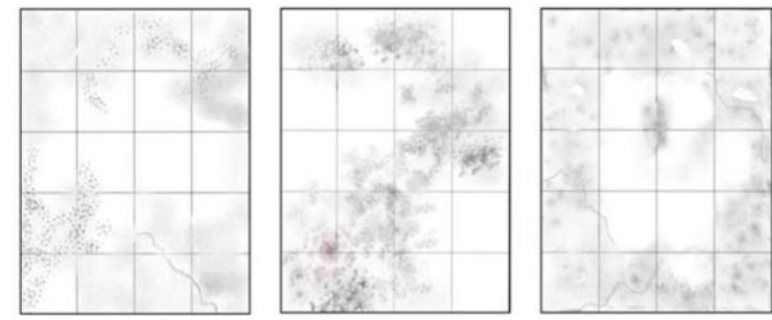

Cấp độ 3 (51-60 \% diện tích nhiễm nấm)
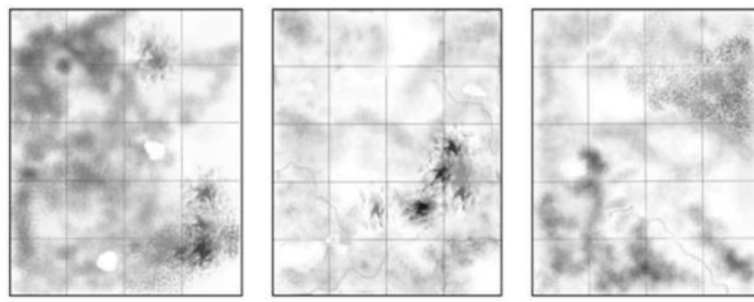

Cấp độ 1 (81-90\% diện tích nhiễm nấm)

\section{Kết quả và thảo luận}

4.1. Kết quả đánh giá khả năng kháng nấm mốc của mẫu gỗ tự nhiên

Tấm mẫu gỗ tự nhiên được sử dụng trong nghiên cứu có kích thước $75 \times 100 \mathrm{~mm}$, chiều dày $9 \mathrm{~mm}$. Các mẫu thử được sắp xếp treo thẳng đứng cách khay đất chứa bào tử nấm một khoảng $75 \mathrm{~mm}$ cho phép không khí lưu thông tự do như được mô tả trong Hình 1. Theo dõi và đánh giá sự phát triển của nấm mốc trên cả hai mặt tấm thử được thực hiện hàng tuần, cấp độ kháng nấm của sản phẩm được đánh giá theo thang 0 đến 10 dựa trên tỷ lệ bề mặt mẫu bị nhiễm nấm sau thời gian phơi nhiễm 4 tuần. Kết quả sự phát triển nấm mốc trên mẫu thử nghiệm được thể hiện trong Hình 2 .

Kết quả nghiên cứu cho thấy mẫu gỗ tự nhiên khi được đặt trong môi trường thuận lợi cho sự phát triển của nấm mốc thì ngay trong tuần đầu tiên (khoảng ngày thứ 3 sau khi đặt mẫu thử vào buồng thử) các bào tử nấm đã bắt đầu xuất hiện và phát triển trên mẫu thử. Hết tuần thứ 2 nấm đã phát triển trên toàn bộ bề mặt mẫu thử nghiệm, theo phương pháp đánh giá cấp độ kháng nấm theo ASTM D3273 thì sản phẩm có cấp kháng nấm mốc là cấp 0 (bề mặt bị tác động hoàn toàn). Điều này cho thấy những loại vật liệu, sản phẩm làm từ gỗ tự nhiên hoặc có nguồn gốc từ vật liệu gỗ tự nhiên như ván gỗ sợi, ván ép,... không được bảo vệ là môi trường rất dễ bị nấm mốc tấn công với tốc độ phát triển nhanh.

\subsection{Kết quả đánh giá khả năng kháng nấm mốc của tấm trần thạch cao}

Nghiên cứu sử dụng ba loại tấm thạch cao phổ biến bao gồm: tấm thạch cao tiêu chuẩn, tấm thạch cao chịu ẩm và tấm thạch cao chống nấm mốc. Kết quả đánh giá được thể hiện trong Bảng 2.

Từ kết quả nghiên cứu cho thấy đối với tấm thạch cao tiêu chuẩn và thạch cao chịu ẩm sau 3 tuần phơi nhiễm các mẫu thử đều không có dấu hiệu cho thấy sự phát triển của nấm mốc. Tuy nhiên sang đến tuần thứ 4 (từ ngày thứ 23-24 kể từ thời điểm đặt) thì nấm
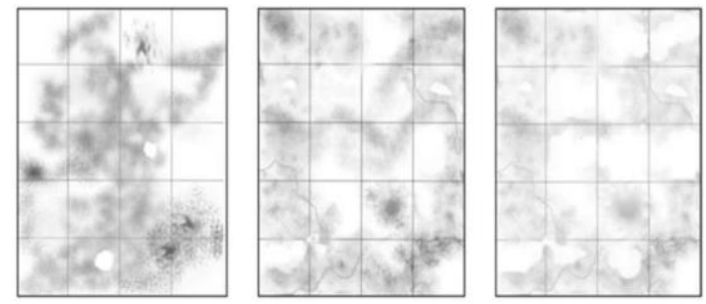

Cấp độ 2 (61-70\% diện tích nhiễm nấm)
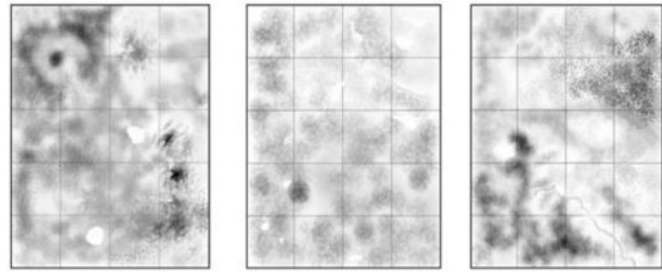

Cấp độ 0 (91-100\% diện tích nhiễm nấm)

mốc đã được hình thành và phát triển trên các tấm mẫu thử và sau 28 ngày phơi nhiễm tỷ lệ diện tích nhiễm mốc trung bình tính được là $11,375 \%$ đối với tấm thạch cao tiêu chuẩn (Hình 3) và 16,192 \% đối với tấm thạch cao chịu ẩm (Hình 4). Xét theo thang đáng giá cấp độ kháng nấm mốc theo ASTM D3273 thì hai nhóm sản phẩm này được xếp hạng Cấp kháng nấm mốc là Cấp $8 / 10$. Kết quả này cho thấy sản phẩm tấm thạch cao hiện cũng đang được sử dụng khá phổ biến trên thị trường vật liệu xây dựng để làm trần và vách ngăn cũng là một đối tượng dễ bị nhiễm nấm mốc, ngay cả sản phẩm tấm thạch cao chịu ẩm cũng vẫn bị nhiễm nấm mốc như tấm thạch cao thông thường. Điều này cũng chỉ ra rằng những vật liệu có khả năng kháng ẩm cũng chưa hẳn có thể kháng được sự phát triển nấm mốc trên vật liệu. Mà để có hiệu quả kháng nấm mốc hay kháng khuẩn nói riêng và kháng vi sinh vật nói chung thì trong thành phần vật liệu phải chứa các tác nhân có hoạt tính kháng vi sinh vật. Như sản phẩm tấm thạch cao siêu kháng ẩm mốc được tiến hành phơi nhiễm trong cùng một điều kiện như đối với tấm thạch cao tiêu chuẩn và thạch cao chịu ẩm. Kết quả đánh giá kháng nấm mốc theo tiêu chuẩn đạt cấp 10/10 (Hình 5).

Cơ chế kháng vi sinh vật của vật liệu phổ biến nhất hiện nay là sử dụng tác nhân kháng vi sinh vật chủ yếu là các hạt nano kim loại hoặc các ion kim loại. Các nghiên cứu phân tích bề mặt vật liệu kháng vi sinh vật cho thấy các hạt nano không có trên bề mặt vật liệu hoặc ở có nồng độ rất thấp so với khối lượng vật liệu. Do vậy cơ chế tiêu diệt vi sinh vật như bào tử nấm hoặc vi khuẩn bám trên vật liệu kháng vi sinh vật phù hợp nhất để phát tán các ion kim loại là sự ăn mòn của các hạt nano hoạt tính có mặt trong nền vật liệu do sự khuếch tán các phân tử nước đi từ môi trường vi sinh vật vào bề mặt của các hạt (Hình 5). Khi nước với oxy hòa tan tiếp xúc các hạt kim loại trong khối polyme, quá trình ăn mòn tiêu chuẩn xảy ra. Sau đó, các ion đến từ quá trình ăn mòn hoặc hòa tan có thể khuếch tán ra ngoài nền vật liệu và cuối cùng được giải phóng phá hủy màng tế bào của vi sinh vật dẫn đến tiêu diệt vi sinh vật bám trên bề mặt vật liệu làm cho vật liệu có khả năng kháng vi sinh vật phát triển. 


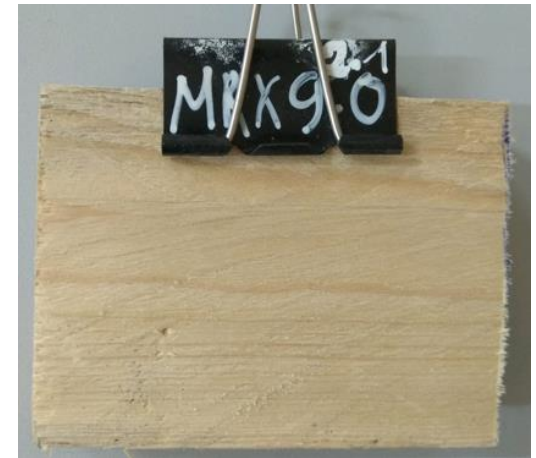

Mẫu chưa thử nghiệm

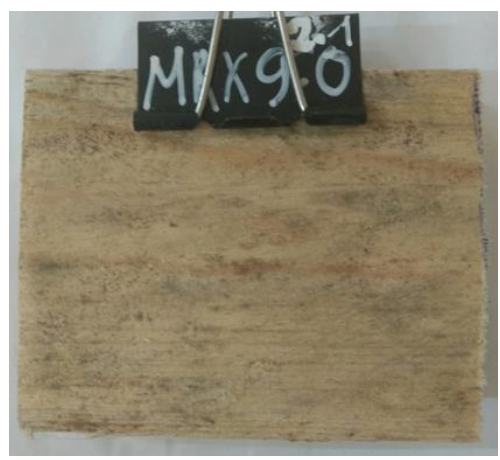

Sau phơi nhiễm 3 tuần

(tỷ lệ nhiễm nấm mốc-100\%)

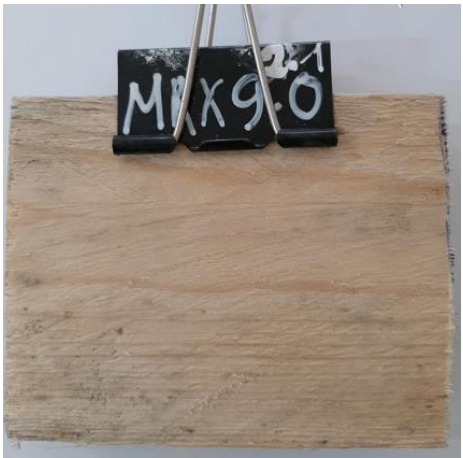

Sau phơi nhiễm 1 tuần

(tỷ lệ nhiễm nấm mốc-42\%)

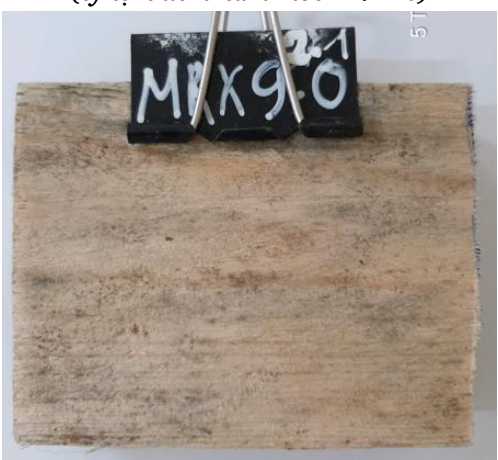

Sau phơi nhiễm 4 tuần

(tỷ lệ nhiễm nấm mốc-100\%)

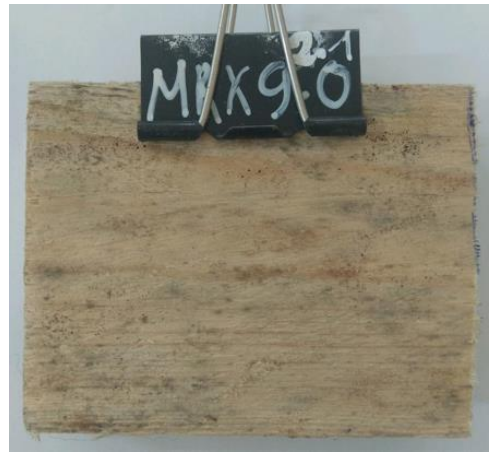

Sau phơi nhiễm 2 tuần

(tỷ lệ nhiễm nấm mốc-100\%)

Hình 2. Kết quả thử nghiệm đánh giá khả năng kháng nấm mốc của gỗ tự nhiên.

Bảng 2. Kết quả đánh giá cấp độ kháng nấm mốc của sản phẩm tấm thạch cao.

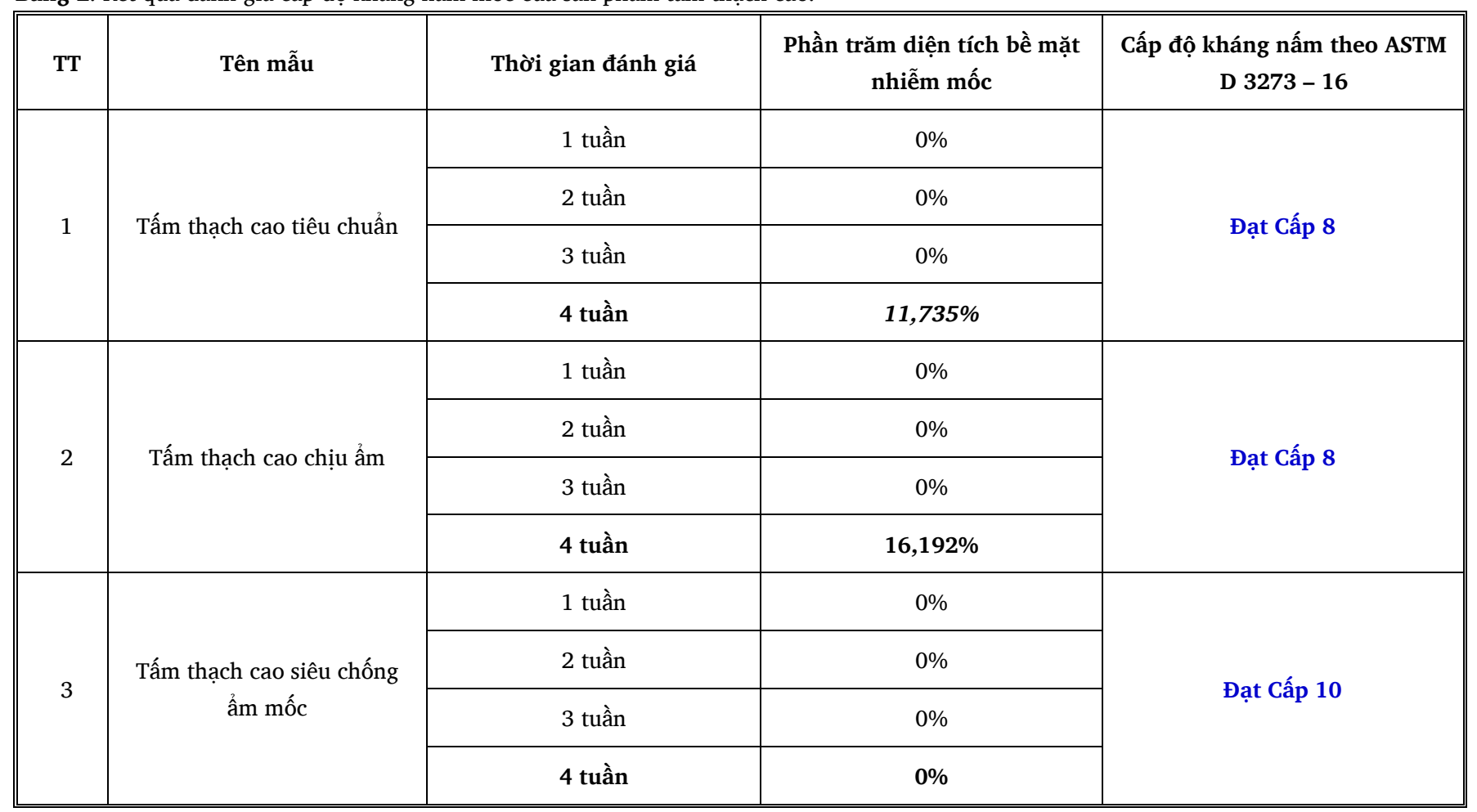



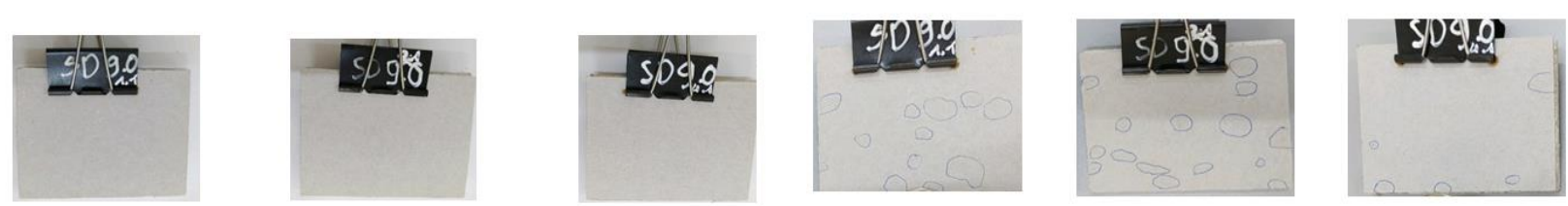

Mẫu thử trước khi phơi nhiễm
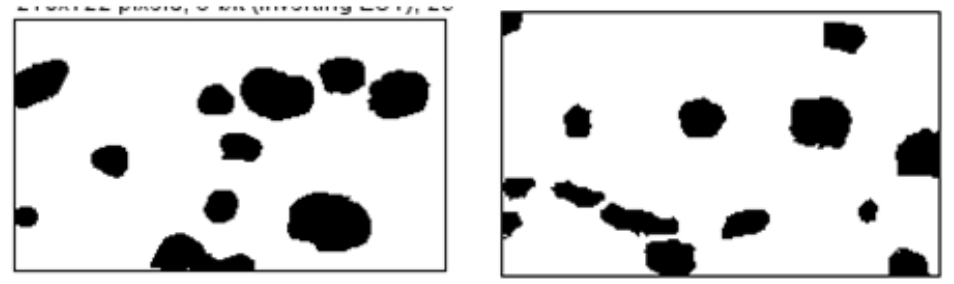

Mẫu thử sau khi phơi nhiễm 28 ngày
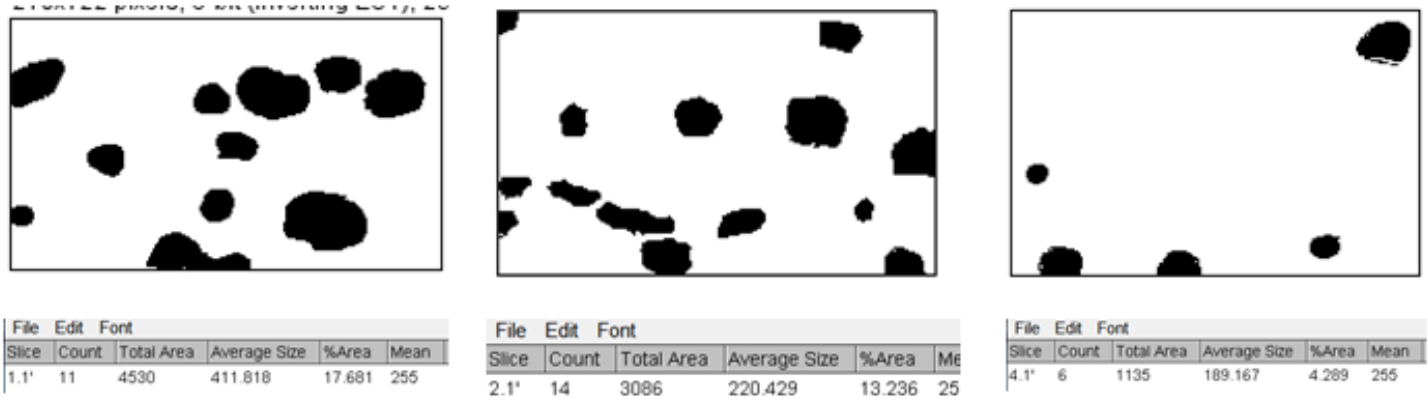

Kết quả phân tích tỷ lệ nhiễm nấm mốc trên tấm thử

Hình 3. Kết quả thử nghiệm khả năng kháng nấm mốc của tấm thạch cao tiêu chuẩn.

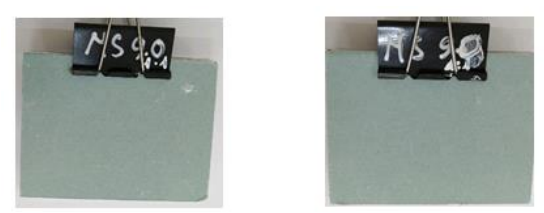

Mẫu thử trước khi phơi nhiễm
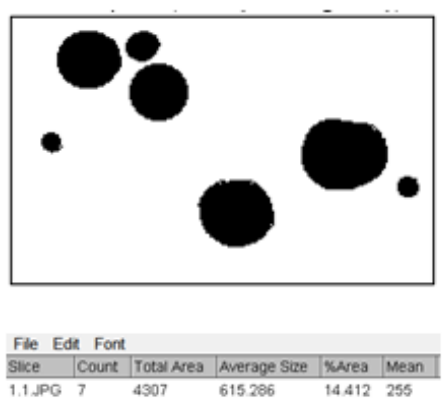
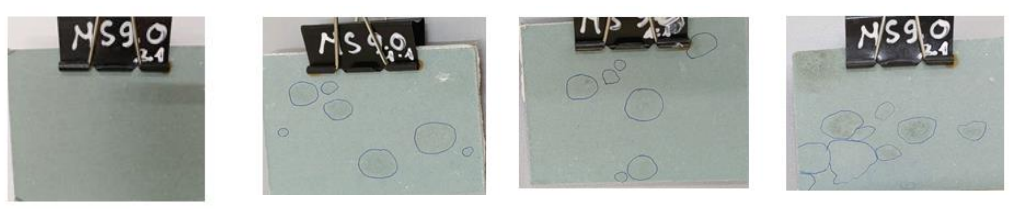

Mẫu thử sau khi phơi nhiễm 28 ngày
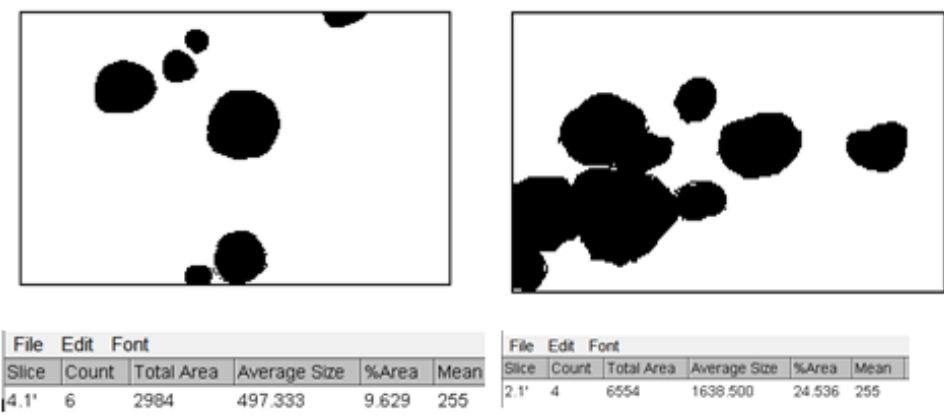

Kết quả phân tích tỷ lệ nhiễm nấm mốc trên tấm thử

Hình 4. Kết quả thử nghiệm khả năng kháng nấm mốc của tấm thạch cao chịu ẩm.

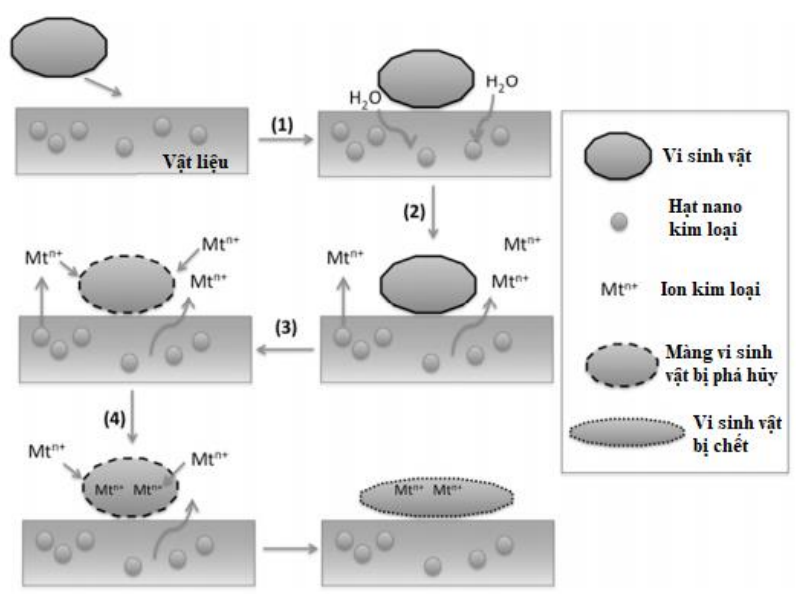

Hình 5. Cơ chế tiêu diệt vi sinh vật của vật liệu chứa hạt nano kim loại. 


\section{Kết luận}

Nghiên cứu đã đưa ra phương pháp tiêu chuẩn được sử dụng để đánh giá khả năng kháng nấm mốc của vật liệu xây dựng là ASTM D3273-16. Đây là phương pháp tiêu chuẩn sử dụng phổ biến trên thế giới để đánh giá khả năng kháng nấm mốc trên bề mặt sản phẩm, vật liệu một cách nhanh chóng. Thử nghiệm ASTM D3273 đặc biệt nhằm mục đích thiết lập đánh giá khả năng chống lại sự lây lan của nấm mốc trong điều kiện nấm phát triển tối ưu. Thử nghiệm này mô phỏng các điều kiện thực tế đối với sản phẩm được thiết kế để sử dụng trong môi trường khí hậu trong nhà phù hợp với điều kiện Việt Nam. Quá trình ủ được diễn ra trong một buồng môi trường được kiểm soát chặt chẽ với các kích thước được tiêu chuẩn hóa trong khoảng thời gian 4 tuần để đánh giá cấp độ kháng nấm mốc của vật liệu.

Nghiên cứu cũng đã tiến hành đánh giá khả năng kháng nấm mốc của một số loại vật liệu xây dựng đang sử dụng phổ biến tại Việt Nam. Kết quả cho thấy phương pháp tiêu chuẩn này đánh giá và phân loại được rõ ràng vật liệu thông thường và vật liệu kháng nấm mốc theo cấp độ kháng nấm mốc từ 0-10. Đây là một căn cứ rõ ràng để kiểm soát và quản lý vật liệu xây dựng có tính năng cao nhằm bảo vệ người tiêu dùng cũng như những nhà sản xuất, phân phối các sản phẩm chất lượng cao tại thị trường Việt Nam.

Trong tương lai nhóm nghiêm cứu đang hướng tới việc xây dựng tiêu chuẩn quốc gia TCVN và các chương trình dán nhãn cho những sản phẩm kháng khuẩn, kháng nấm mốc theo từng cấp bậc để người tiêu dùng dễ dàng nhận biết các sản phẩm bảo vệ sức khỏe. Bên cạnh đó nhóm nghiên cứu cũng sẽ mở rộng các hướng nghiên cứu đánh giá độ bền vật liệu xây dựng dưới tác động của vi sinh vật, đồng thời cũng tiến hành nghiên cứu phát triển các sản phẩm vật liệu mới có khả năng kháng khuẩn, kháng nấm mốc phù hợp với điều kiện kinh tế kỹ thuật của Việt Nam.

\section{Tài liệu tham khảo}

[1]. Chi P. Hoang, Kerry A. Kinney, Richard L. Corsi, Paul J. Szaniszlo, "Resistance of green building materials to fungal growth". International Biodeterioration \& Biodegradation 64, 104-113, 2010. https://doi.org/10.1016/j.ibiod.2009.11.001

[2]. https://www.cdc.gov/mold/faqs.htm

[3]. Elisabeth Heseltine, Jerome Rosen, "WHO guidelines for indoor air quality : dampness and mould", World Health Organization, 2009.

[4]. Phạm Ngọc Đăng, Trần Thị Minh Nguyệt, "Nghiên cứu xây dựng tiêu chuẩn mới về chất lượng không khí trong nhà ở và nhà công cộng”, Tạp chí Môi trường số 1, 2021.

[5]. ASTM D3273 - 16 Standard Test Method for Resistance to Growth of Mold on the Surface of Interior Coatings in an Environmental Chamber.

[6]. Afnan Al-Hunaiti, Sharif Arar, Martin Täubel, Darren Wraith, Androniki Maragkidou, Anne Hyvärinen, Tareq Hussein, "Floor dust bacteria and fungi and their coexistence with PAHs in Jordanian indoor environments", Science of the total environment, pp.940-945, 2017.

https://doi.org/10.1016/j.scitotenv.2017.05.211
[7]. Rachel I.Adams, Seema Bhangar, Karen C.Dannemiller, Jonathan A.Eisen, et all "Ten questions concerning the microbiomes of buildings". Building and Environment, 224-234 https://doi.org/10.1016/j.buildenv.2016.09.001

[8]. Johansson P., Svensson T., Ekstrand-Tobin A, "Validation of critical moisture conditions for mould growth on building materials", Building and Environment, 62: 201-209, https://doi:10.1016/j.buildenv.2013.01.012.

[9]. Bashir U., Hafeez, "Deterioration of painted wall surface by fungal saprobes: isolation and identification", Pakistan Journal of Phytopathology, 28: 09 13, 2016

[10]. Parjo U. K. et al, "Effect of Fungal Growth on the Surface of Painted Plasterboards", Advances in Environmental Biology, 9(20): 15-19, 2017.

[11]. Mensah-Attipoe, "Comparison of methods for assessing temporal variation of growth of fungi on building materials", Microbiology, 162, 1895-1903, 2016. https://doi:10.1099/mic.0.000372.

[12]. Andersen B. et al, "Associations between Fungal Species and Water-Damaged Building Materials", Applied and environmental microbiology, 77 (12): 4180-4188, 2011, https://doi:10.1128/AEM.02513-10.

[13]. Viitanen.HA, "Modelling the time factor in the development of mould fungi Effects of critical humidity and temperature conditions in pine and spruce sapwood". Holzforschung 51: 6- 14, 1997.

[14]. Pasanen.A-L, Juutinen.T, Jantunen.MJ, Kalliokoski.P, "Occurrence and moisture requirements of microbial growth in building materials". Int.Biodet.Biodegr. 30: 273-283, 1992.

[15]. Webb.JS, Nixon.M, Eastwood.IM, Greenhalg.M , Robson.GD, Handley.PS, "Fungal colonization and biodeterioration of plasticized polyvinyl chloride", Appl.Env.Microb. $\quad 66: \quad 3194-\quad 3200, \quad 2000$, https://doi:10.1128/AEM.66.8.3194-3200.2000.

[16]. Tanaka. H, Wang.P-L, Yamada.O, Tamura.H, "Yellow pigments of Aspergillus niger and A. awamori.I. Isolation of aurasperone $A$ and related pigments", Agric.Biol.Chem. 30: 107-113, 1966.

[17]. Ehrlich. KC, DeLucca. AJ, Ciegler.A, "Naphtho-gamma-pyrone production by Aspergillus niger isolated from stored cottonseed", Appl.Env.Microb. 48: 1-4, 1984. 